\title{
QTL Mapping in Tropical Maize: I. Genomic Regions Affecting Leaf Feeding Resistance to Sugarcane Borer and Other Traits
}

\author{
M. Bohn, M. M. Khairallah, D. González-de-León, D. A. Hoisington, H. F. Utz, J. A. Deutsch, \\ D. C. Jewell, J. A. Mihm, and A. E. Melchinger*
}

\begin{abstract}
Sugarcane borer (SCB), Diatraea saccharalis Fabricius, is a serious pest in tropical maize production areas in the Americas. Little is known about the genetic resistance of maize genotypes to this pest. In this study, we mapped and characterized quantitative trait loci (QTL) affecting resistance to the leaf feeding generation of SCB (1SCB), grain yield under both protection (GYP) and infestation (GYI) with SCB larvae, and plant height (PHT). A total of $171 F_{2}$ genotypes derived from cross CML131 (susceptible) $\times$ CML67 (resistant) and 93 RFLP marker loci were used in QTL analyses. $F_{3}$ lines were evaluated for the above traits and grain yield reduction (GYR) in field experiments with two replications at two or three tropical environments. Resistance was assessed by rating leaf feeding damage after artificial infestation with SCB larvae. The method of composite interval mapping with selected markers as cofactors was used for detection and characterization of QTL. Resistance to $1 \mathrm{SCB}$ was significantly affected by 10 putative QTL on Chromosomes $1,2,5,7,8,9$, and 10. These showed predominantly additive gene action and explained $65.0 \%$ of the phenotypic variance and $93.5 \%$ of the genetic variance in a simultaneous fit. Six QTL for GYP, five QTL for GYI with primarily dominant genetic effects, and four QTL for PHT with primarily additive genetic effects were identified, explaining in total about one third of the phenotypic variance for the respective trait. No more than one putative QTL was found to be common between different characters. QTL $\times$ environment interaction was found to be significant for 1SCB ratings only. Based on these data, prospects for improving 1SCB resistance by marker-assisted breeding are promising.
\end{abstract}

$I^{N}$ N CENTRAL AND LATIN AMERICA the sugarcane borer (SCB), Diatraea saccharalis Fabricius, can cause extensive damage in maize production fields. In the smallscale, low-input farming systems prevailing in this region, low yield stability is partly due to the highly variable damage caused by SCB. Moths of SCB deposit their eggs on leaves of maize plants during the whorl stage. After hatching, larvae migrate into the whorl and feed on the epidermis for 9 to $10 \mathrm{~d}$. Subsequently, larvae move outside of the stalk and start penetrating into the stalk for further development and pupation. After 35 to $50 \mathrm{~d}$, the second-generation adults appear. In tropical environments, up to seven generations can develop annually.

Total yield loss due to maize borer infestation can be divided into several components. Up to $20 \%$ yield loss can be attributed to the first-generation leaf feeding (Scott

M. Bohn, H.F. Utz, and A.E. Melchinger, Institute of Plant Breeding, Seed Science, and Population Genetics, Univ. of Hohenheim, 70593 Stuttgart, Germany; M.M. Khairallah, D. González-de-León, and D.A. Hoisington, CIMMYT Int., Lisboa 27, Apdo Postal 6-641, Mexico, D.F., 06600 Mexico, D.C.; Jewell, CIMMYT Int., P.O. Box MP 154, Mount Pleasant, Zimbabwe; J.A. Deutsch, RR4 Box 302, Marshall, MO 65340; J.A. Mihm, French Agric. Res. RR2 Box 294, Lamberton, MN 56152. Received 26 Sept. 1995. *Corresponding author (pzaem@unihohenheim.de).

Published in Crop Sci. 36:1352-1361 (1996). and Davis, 1974). Successive generations cause less direct damage, but lead to increased indirect losses as a consequence of lodging due to tunneling. Estimated average yield losses due to SCB range from 14 to $50 \%$ (Hinderliter, 1983).

SCB-resistant maize genotypes were identified in germplasm originating from the Caribbean Islands (Elias, 1970) and in CIMMYT Populations 27 (Mihm, 1985), 390, and 590 (Mihm et al., 1991). Resistance of Population 27 was found to be polygenically inherited with primarily additive gene action (Hinderliter, 1983). Beyond this, little is known about the mechanisms of 1SCB resistance and the number of genes involved, as well as their location in the maize genome.

At CIMMYT, germplasm conferring resistance against a number of species of corn borer, including SCB, was combined to form a multiple-borer-resistant (MBR) population (Smith et al., 1989). The level of resistance to these insect species was significantly improved by $S_{1}$ recurrent selection. However, recurrent selection and screening techniques for evaluating insect resistance are laborious and time consuming. These problems may be overcome by marker-assisted selection (MAS) for those genomic regions that significantly improve insect resistance without adversely affecting other important agronomic traits.

Application of MAS requires knowledge about the location and effects of genetic factors influencing the target traits. With the advent of new classes of molecular markers such as RFLPs, it has become feasible to dissect complex quantitative traits at least partly into their underlying Mendelian factors, also referred to as QTL. Since the pioneering paper of Paterson et al. (1988), numerous studies have been conducted to map QTL for yield, quality traits, and resistance to insects and other pests in many crop species including maize (for review, see Lee, 1995).

While no QTL studies have yet been published on the resistance in maize to tropical stem borers, encouraging reports are available on the mapping of QTL conferring resistance to the first-generation (1ECB, leaf feeding) and the second-generation (2ECB, sheath and collar feeding and stem tunneling) of the European corn borer (ECB), Ostrinia nubilalis Hübner, in U.S. Cornbelt germplasm. In a population of $150 \mathrm{~F}_{3}$ lines derived from the cross between Mo17 (susceptible) and H99

\footnotetext{
Abbreviations: 1ECB, first generation of European corn borer; ISCB, first generation of sugarcane borer; 1SWCB, first generation of southwestern corn borer; cM, centimorgan; CIM, composite interval mapping; CIMMYT, International Maize and Wheat Improvement Center; GYI, grain yield under 1SCB infestation; GYP, grain yield under protection; GYR, grain yield reduction due to $1 \mathrm{SCB}$ infestation; LOD, $\log _{10}$ odds ratio; MAS, marker-assisted selection; P1, parent one; P2, parent two; PHT, plant height; QTL, quantitative trait locus (or loci, depending on the context); RFLP, restriction fragment length polymorphism.
} 
(resistant), Schön et al. (1991) identified four QTL significantly affecting $1 \mathrm{ECB}$ resistance on Chromosomes $1,4,6$, and 9. For resistance against 2ECB, Schön et al. (1993) found seven QTL in a population of 300 $\mathrm{F}_{3}$ lines derived from cross B73 (susceptible) $\times \mathrm{B} 52$ (resistant). Beavis et al. (1994) used topcrosses and $F_{4}$ progeny of $112 \mathrm{~F}_{2}$-derived lines from cross $\mathrm{B} 73 \times \mathrm{Mo} 17$ for QTL analyses and identified three QTL significantly affecting 2 ECB resistance on Chromosomes 7, 8, and 9.

In this study, we mapped and characterized QTL for resistance to $1 \mathrm{SCB}$ feeding and related agronomic traits in a population of $\mathrm{F}_{3}$ lines derived from the cross of two tropical maize inbreds, one highly resistant and the other highly susceptible to 1SCB. Objectives of our study were to: (i) estimate the number and the genomic positions of QTL with significant gene effects involved in trait expression, (ii) determine the size and type of their genetic effects, and (iii) provide information on the most efficient design of conventional breeding programs and the prospects of MAS.

\section{MATERIALS AND METHODS}

\section{Plant Materials}

Two near-homozygous inbred lines, CML131 and CML67, were used as the parent material. CML131, a subtropical intermediate white dent line, was selected from CIMMYT Population 42 and is highly susceptible to leaf feeding by SCB and southwestern corn borer (SWCB), Diatraea grandiosella Dyar. CML67 is a tropical yellow semi-dent line selected out of Antigua Group 2; it is known to be highly resistant to SCB, SWCB, and fall armyworm, Spodoptera frugiperda (J.E. Smith) (CIMMYT Maize Program, 1991; Mihm et al., 1991).

During the 1991 summer season, $F_{2}$ plants derived from two randomly chosen $F_{1}$ plants from the cross CML131 $\times$ CML67 were grown in Tlaltizapán, State of Morelos, Mexico, and selfed to produce $215 \mathrm{~F}_{3}$ lines. Leaf samples were taken from a random subset of 190 parental $F_{2}$ plants for subsequent RFLP assays, of which 171 were in common with the $215 \mathrm{~F}_{3}$ lines used in the field trials. The $215 \mathrm{~F}_{3}$ lines were sib-mated the following season to produce enough seed for field trials.

\section{RFLP Assays}

Genomic DNA was extracted from leaf material and digested with restriction enzymes EcoRI and HindIII. The resulting DNA fragments were separated by agarose gel electrophoresis and transferred onto uncharged membranes by Southern blotting. Hybridization of membranes was performed with 93 single or low-copy genomic DNA probes from the standard probe collection available from the University of Missouri (Gardiner et al., 1993). These enzyme-probe combinations yielded a total of 100 RFLP marker loci. Probes were labeled with digoxigenin-dUTP and DNA fragments were detected by means of the chemiluminescence antidigoxigenin-AMPPD protocol of Hoisington et al. (1994).

\section{Agronomic Trials}

Experiments with infestation of SCB larvae and those under protection (insecticide application without infestation) were conducted in the winter seasons (November through May) 1992 and 1993 at CIMMYT's Tlaltizapán, Mexico, experimental station (subtropical environment, 940-m elevation, $18^{\circ} \mathrm{N}$ ) and in the winter season of 1993 at CIMMYT's Poza Rica,
Mexico, station (lowland tropical environment, 60-m elevation, $\left.21^{\circ} \mathrm{N}\right)$. Each year-location combination was treated as an environment in the subsequent statistical analyses. Each experiment included 240 entries: $215 \mathrm{~F}_{3}$ lines and the parental inbred lines as multiple entries. The experimental design was a 24by-10 alpha design with two replications and single-row plots $0.75 \mathrm{~m}$ apart and $5.0 \mathrm{~m}$ long in 1992, and $2.5 \mathrm{~m}$ long in 1993 . The trials were over-planted and thinned to 24 plants per row in 1992 and 12 plants per row in 1993, corresponding to 60000 plants ha ${ }^{-1}$. All experiments were planted and harvested by hand as grain trials.

For evaluating the level of resistance against 1SCB, every plant was artificially infested with 30 to 45 neonate SCB larvae at the six- to eight-leaf stage (mid-whorl). Freshly hatched larvae were mixed with maize-cob grits and applied into the plant whorl using a mechanical dispenser (Mihm, 1983). Leaf feeding damage by SCB was assessed two to three weeks after infestation using a rating scale from 1 (no visible leaf damage) to 10 (dead growing point, all leaves with long lesions) as described by Thome et al. (1992).

Other traits for which data were collected in two environments (Tlaltizapán, winter seasons of 1992 and 1993) included (i) plant height (PHT) in centimeters, measured on an individual plant basis from soil level to lowest tassel branch in the protected trials; (ii) grain yield per plant (g plant ${ }^{-1}$ ), measured in protected trials (GYP); (iii) grain yield per plant ( g plant $^{-1}$ ), measured in infested trials (GYI); and (iv) grain yield reduction (\%), calculated as the percent reduction of yield of an entry in infested trials compared with protected trials, using in both cases the adjusted entry mean (GYR). Both GYP and GYI were determined by dividing the total grain yield per plot (standardized to $155 \mathrm{~g} \mathrm{H}_{2} \mathrm{O} \mathrm{kg}^{-1}$ ) by the number of plants per plot.

\section{Data Analyses}

Analyses of variance were performed on field data from each experiment within each environment. Adjusted entry means and effective error mean squares were used to compute the combined analyses of variance and covariance across environments for experiments with and without ISCB infestation. The sums of squares for entries ( $239 \mathrm{df}$ ) were subdivided into the variation among $F_{3}$ lines ( $214 \mathrm{df}$ ) and the orthogonal contrasts among the means of $F_{3}$ lines $\left(\bar{F}_{3}\right)$ vs. the midparental value $(\overline{\mathrm{P}}=(\mathrm{P} 1+\mathrm{P} 2) / 2)$ and $\mathrm{P} 1$ vs. $\mathrm{P} 2$. A corresponding subdivision was conducted on the entry $X$ environment sums of squares.

Components of variance for the $F_{3}$ lines were computed considering all effects in the statistical model as random. Estimates of variance components $\sigma^{2}$ (error variance), $\sigma_{\mathrm{ge}}^{2}$ (genotype $\times$ environment interaction variance), and $\sigma_{\mathrm{g}}^{2}$ (genetic variance) of $F_{3}$ lines and their standard errors were calculated as described by Searle $(1971$, p. 475$)$. The variance among $\mathrm{F}_{3}$ line means $\left(\hat{\sigma}_{\mathrm{p}}^{2}\right)$ was obtained by dividing the mean square of $F_{3}$ lines by the number of environments times two replications. Heritabilities $\left(\hat{h}^{2}\right)$ for $\mathrm{F}_{3}$ lines were calculated on an entry-mean basis and asymmetrical confidence intervals on $\hat{h}^{2}$ were estimated. Phenotypic $\left(r_{\mathrm{p}}\right)$ and genotypic $\left(r_{\mathrm{g}}\right)$ correlation coefficients were calculated among agronomic traits in $\mathrm{F}_{3}$ lines by applying standard procedures (Mode and Robinson, 1959). Estimates of $r_{\mathrm{g}}$ were calculated only when estimates of $\sigma_{\mathrm{g}}^{2}$ were significantly $(P<0.01)$ greater than zero for both traits under consideration.

Segregation at each marker locus was checked for deviations from expected Mendelian segregations $(1: 2: 1,3: 1)$ and an allele frequency of 0.5 by standard $\chi^{2}$ tests. Because multiple tests were performed (corresponding to the number of RFLP markers assayed), appropriate Type I error rates were deter- 
mined by the sequentially rejective Bonferroni procedure described by Holm (1979). Estimates of the level of heterozygosity $(\%)$ of parental $\mathrm{F}_{2}$ plants relative to the heterozygosity in the $F_{1}$ were obtained by dividing the observed number of heterozygous marker loci by the total number of scorable marker loci in the respective plant. Likewise, the percentage of CML131 genome in each $F_{2}$ plant was determined by dividing the sum of all CML131 marker alleles by twice the number of scorable marker loci in the respective plant.

A linkage map based on the $190 \mathrm{~F}_{2}$ individuals and 100 RFLP marker loci was constructed by means of the software package MAPMAKER (Lander et al., 1987). Linkage between two markers was declared significant in the two-point analyses when the LOD score ( $\log _{10}$ of the likelihood odds ratio) exceeded the threshold of 3.0. After determination of linkage groups and the correct linear arrangement of marker loci along the chromosomes, recombination frequencies between marker loci were estimated by multi-point analyses and transformed into centimorgan (cM) by Haldane's (1919) mapping function.

The QTL analysis was performed with on the subset of 171 $F_{2}$ individuals for which both molecular and phenotypic data were available. For mapping of QTL and estimation of their effects, the recently proposed method of composite interval mapping (Jansen and Stam, 1994; Zeng, 1994) was employed. All necessary computations for this method were performed with the newly developed software package PLABQTL (Utz and Melchinger, 1995), which employs interval mapping by the regression approach (Haley and Knott, 1992) in combination with the use of selected markers as cofactors. The underlying model [as proposed by Zeng (1994) with modifications by Utz and Melchinger (1994)] can be written as follows:

$$
y_{j}=m+b_{1}^{*} x_{a j l}^{*}+b_{2}^{*} x_{d j l}^{*}+\sum_{k} b_{k} x_{j k}+\varepsilon_{j} \text {. }
$$

Here, $y_{j}$ denotes the phenotypic trait value of the $j$ th $F_{3}$ line; $m$ is the mean phenotypic value of $F_{3}$ lines with genotype QQ at the putative QTL; $b_{1}^{*}$ and $b_{2}^{*}$ are the additive $(a)$ and the dominance $(d)$ effects, as defined by Falconer (1989, p. 112), of the putative QTL in the marker interval $(l, l 1+1)$ under consideration; $x_{a j l}^{*}$ and $x_{b j l}^{*}$ are conditional expectations of the dummy variables $A$ and $D$ given the observed genotype at the flanking marker loci, where $A$ assumes values 0,1 , and 2 , and $D$ assumes values $0,0.5$, and 0 , when the genotype at the putative QTL is QQ, Qq, or $\mathrm{qq}$, respectively $(D=0.5$ rather than 1.0 for heterozygotes $\mathrm{Qq}$, because phenotypic traits were evaluated for $F_{3}$ lines and not $F_{2}$ plants, hence only half of the dominance effect is present); $b_{k}$ is the partial regression coefficient of phenotype $y_{j}$ on the $k$ th (selected) marker; $x_{j k}$ is a dummy variable (cofactor) taking values 1,0 or -1 depending on whether the marker genotype of individual $j$ at marker locus $k$ is $M_{k} M_{k}, M_{k} m_{k}$, or $m_{k} m_{k}$, respectively; $\varepsilon_{j}$ is a residual variable for the $j$ th $F_{3}$ line. Cofactors were selected by stepwise regression. Final selection was for the model that minimized Akaike's information criterion (for details, see Jansen, 1993). The set of cofactors selected for the data averaged across environments was also applied to identify QTL in individual environments.

Following Zeng (1994), we employed a simple interval (likelihood ratio) test, in which the maximized likelihood $\left(\mathrm{L}_{\mathrm{l}}\right)$ of the model with the putative QTL is compared with the maximum likelihood $\left(\mathrm{L}_{0}\right)$ of the model without the QTL (both models include all selected cofactors, except when a cofactor was identical to one of the markers flanking the interval under consideration). The threshold of the LOD score $\log _{10}\left(\mathrm{~L}_{1} / \mathrm{L}_{0}\right)$ for declaring a putative QTL significant was chosen to be 2.5. According to recent results from simulation studies (Jansen, 1994), this threshold ensures a comparisonwise Type I error of $P<0.01$ in the mapping of QTL for the sparse map case and reduces the chances of a Type II error. Following common practice, estimates of QTL positions were obtained at the point where the LOD score assumes its maximum in the region under consideration. A one-LOD support interval was constructed for each QTL as described by Lander and Botstein (1989). QTL with non-overlapping support intervals were regarded as being different.

The phenotypic variance $\left(\hat{\sigma}_{p}^{2}\right)$ explained by a single QTL was obtained by the square of the partial correlation coefficient $\left(R^{2}\right)$. Estimates of the additive $\left(a_{\mathrm{i}}\right)$ and dominance $\left(d_{\mathrm{i}}\right)$ effects of the $i$ th QTL and the total $\hat{\sigma}_{\mathrm{p}}^{2}$ explained by all QTL, as well as the total LOD score, were obtained by fitting a model including all putative QTL for the respective trait. The hypothesis of no additive or dominance effect of the QTL $\left(H_{0}: a_{1}=\right.$ 0 or $H_{0}: d_{\mathrm{i}}=0$ ) was tested by an $F$-test using the test statistic $F=$ (partial sum of squares of the single QTL effect)/(residual mean squares of the model fitting all detected QTL simultaneously). Following Stuber et al. (1987), the ratio DR $=\left(\left|d_{\mathrm{i}}\right| /\right.$ $\left|a_{\mathrm{i}}\right|$ ) was used to describe the type of gene action at each QTL: additive for $\mathrm{DR}<0.2$; partial dominance for $0.2 \leq \mathrm{DR}<$ 0.8 ; dominance for $0.8 \leq \mathrm{DR}<1.2$; overdominance for $\mathrm{DR} \geq 1.2$

The QTL $\times$ environment interaction variance was estimated by fitting a model to the $\alpha$-design-adjusted entry means from each environment which included all QTL detected in the analysis of means across environments. The sum of squares for genotypes obtained from the combined ANOVA was subdivided into the variation due to regression on the detected QTL $\left(\mathbf{M}_{q}\right)$ and the residual variation $\left(\mathbf{M}_{r}\right)$. A similar subdivision was performed for the genotype $X$ environment interaction sum of squares yielding the respective mean squares $\mathbf{M}_{q e}$ and $\mathbf{M}_{r e}$. The total genetic variance explained by all QTL in the model $\left(\hat{\sigma}_{q}^{2}\right)$ was estimated by equating the mean squares to the expected mean squares as given by Bliss $(1967$, p. 426) and Knapp (1994). In contrast to the $R^{2}$ value, $\hat{\sigma}_{q}^{2}$ is not biased by QTL $\times$ environment interactions. Hence, the proportion of $\hat{\sigma}_{\mathrm{g}}^{2}$ explained by all QTL in the model $\left(Q^{2}\right)$ was estimated as $\mathrm{Q}^{2}=\hat{\sigma}_{\mathrm{q}}^{2} / \hat{\sigma}_{\mathrm{g}}^{2}$. The hypothesis of no significant $\mathrm{QTL} \times$ environment interaction was tested by using an $F$-test on the test statistic $F=\mathbf{M}_{q e} / \mathbf{M}_{r e}$. When this hypothesis was rejected, QTL $X$ environment interaction was tested for each ith QTL by applying an $F$-test using the test statistic $F=\left(\mathbf{M}_{q e}\right)_{i} / \mathbf{M}_{r e}$, where $\left(\mathbf{M}_{q e}\right)_{i}$ refers to the sum of squares attributable to QTL $X$ environment interactions of the $i$ th QTL divided by the respective df. Appropriate Type I error rates were determined by the sequentially rejective Bonferroni procedure corresponding to the number of fitted QTL effects.

\section{Segregation and Linkage of RFLPs}

By applying the sequentially rejective Bonferroni procedure, we detected no significant deviations of observed genotype frequencies from the Mendelian expectations for the 100 RFLP marker loci. The proportion of CML131 genome among the $190 \mathrm{~F}_{2}$ individuals followed approximately a normal distribution and ranged from 21.5 to $67.5 \%$, with mean $\bar{x}=49.5 \%$ and standard deviation SD $=7.3 \%$. The level of heterozygosity in $\mathrm{F}_{2}$ plants also displayed a normal distribution and varied from 23.5 to $72.6 \%$, with $\overline{\mathrm{x}}=50.6 \%$ and $\mathrm{SD}=9.3 \%$. Our RFLP linkage map based on this tropical maize germplasm (Fig. 1) is in good agreement with maps that have been published for temperate maize germplasm (Burr et al., 1988; Gardiner et al., 1993). Two loci (bnl13.05a and bnl3.04) were not significantly linked $(\mathrm{LOD}<3.0)$ to any of the 10 linkage groups. However, the data supported placement of bnll3.05a on Chromo- 

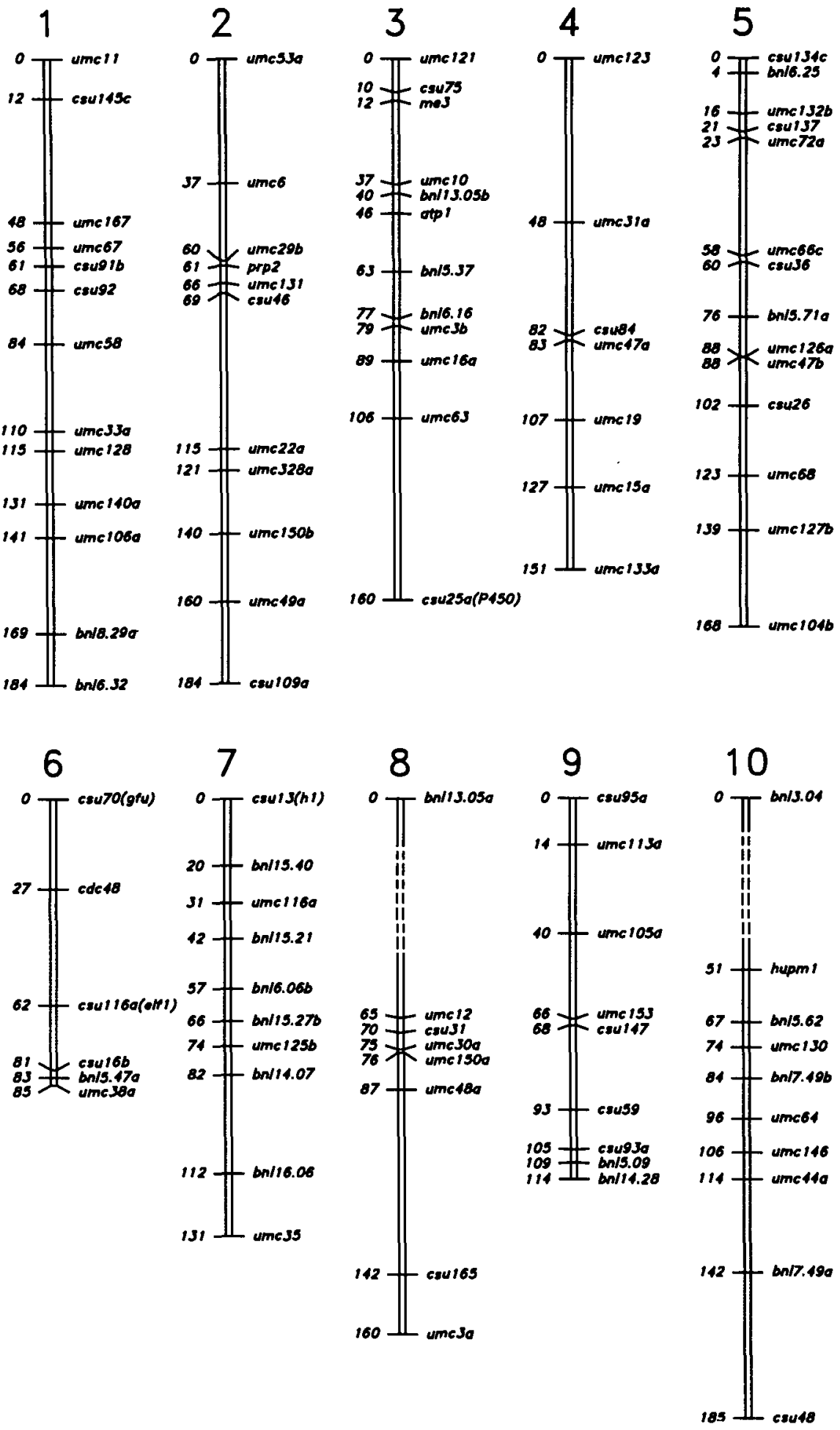

Fig. 1. Genetic map of maize based on $190 F_{2}$ individuals derived from cross CML131 $\times$ CML67 for 100 RFLP marker loci. Dashed areas between markers indicate that linkage was not significant (LOD $<3.0$ ). Numbers to the left of the chromosomes indicate distance, relative to the first marker, in cM. The short arm of each chromosome is shown toward the top of the page.

some 8 and bnl3.04 on Chromosome 10 in accordance with published maps. The 100 RFLP marker loci span a map distance of $1535.5 \mathrm{cM}$ with an average interval length of $17.1 \mathrm{cM}$.

\section{Agronomic Trait Analysis}

Means of parental inbred lines CML131 and CML67 differed significantly $(P<0.01)$ from each other for all measured traits except GYI (Table 1). The parental lines represented the extremes of the distribution only for 1 SCB ratings. The orthogonal contrast of the mean performance of the two parent lines $(\bar{P})$ and the overall mean of the $215 \mathrm{~F}_{3}$ lines $\left(\overline{\mathrm{F}}_{3}\right)$ was significant $(P<0.05)$ for all traits except $1 \mathrm{SCB}$ ratings. $\bar{F}_{3}$ was significantly greater than $\overline{\mathrm{P}}$ for GYP, GYI, and PHT, while the reverse applied to GYR. 
Table 1. Means of parents CML131 and CML67, and $215 \mathrm{~F}_{3}$ lines derived from their cross, plus estimates of variance components and heritabilities among $F_{3}$ lines for 1SCB ratings, grain yield under protection (GYP), grain yield under infestation (GYI), grain yield reduction (GYR), and plant height (PHT). $\dagger$

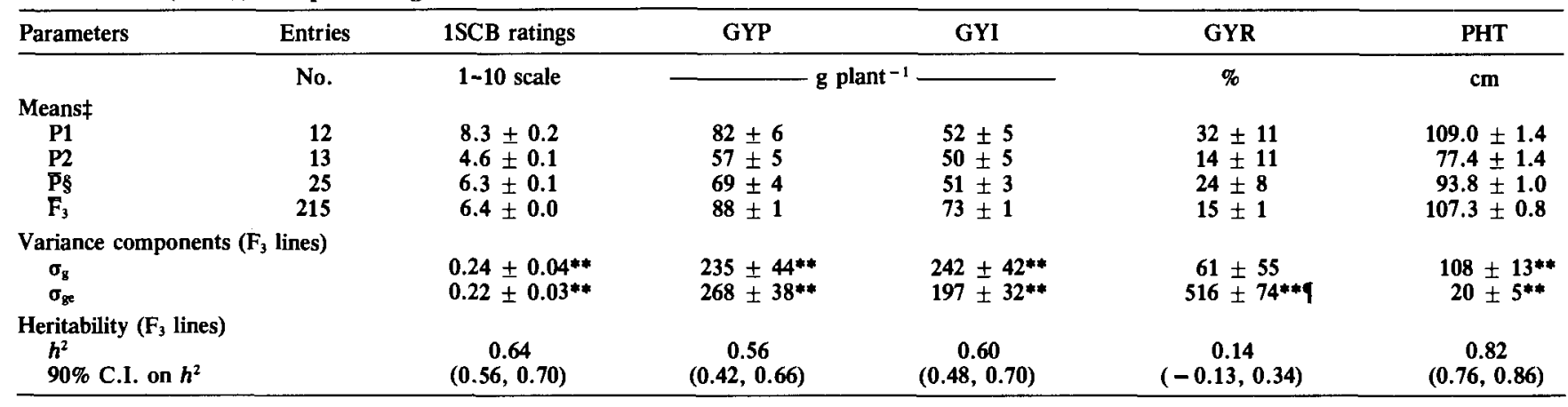

** Variance component was significant at the 0.01 probability level.

$\dagger$ 1SCB rating, measured in three environments; GYP, GYI, GYR, and PHT, measured in two environments.

$\mp$ Standard errors are attached.

$\$ \mathrm{P}=$ mean of CML131 and CML67, $\mathrm{F}_{3}=$ mean of $\mathrm{F}_{3}$ lines.

1 Estimate of $\sigma_{g e}^{2}$ is confounded with $\sigma^{2}$.

Genotypic variances among $\mathrm{F}_{3}$ lines $\left(\hat{\sigma}_{\mathrm{g}}^{2}\right)$ were highly significant $(P<0.01)$ for all traits but GYR (Table 1$)$. Estimates of $\sigma_{\mathrm{ge}}^{2}$ were significantly $(P<0.01)$ greater than zero for all traits. Heritability estimates were intermediate $(0.56$ for GYP) to high ( 0.82 for PHT) for all traits except GYR.

Phenotypic $\left(r_{\mathrm{p}}\right)$ and genotypic $\left(r_{\mathrm{g}}\right)$ correlations among agronomic traits of the $F_{3}$ lines were highly significant $(P<0.01)$, but less than \pm 0.45 for most trait combinations (Table 2). Exceptions were GYP and GYI with $r_{\mathrm{p}}=0.62$ and $r_{\mathrm{g}}=0.98$. 1SCB ratings were not associated with GYR. Relative heterozygosity of $F_{2}$ plants (determined from RFLP data) was significantly $(P<$ $0.01)$ correlated with GYP, GYI, and PHT in the descending $F_{3}$ lines, yet all correlations were less than \pm 0.30 . The estimated percentage of CML131 genome in $\mathrm{F}_{2}$ plants displayed a highly significant $(P<0.01)$ correlation $\left(r_{\mathrm{p}}=0.60\right)$ with 1 SCB ratings, but correlations to other agronomic traits were low.

\section{QTL Analyses}

QTL analyses were performed using genotypic data for 100 RFLP marker loci and phenotypic data combined across environments as well as from individual environ- ments. For 1SCB ratings, there was considerable variation among QTL likelihood curves obtained for individual environments (Fig. 2). The LOD curves for the combined data showed peaks above the 2.5 LOD score threshold for those cases where either one QTL was detected in at least one environment, or LOD curves below the threshold displayed similar trends for at least two environments. The global test for QTL $\times$ environment interactions was significant $(P<0.01)$ for 1 SCB ratings only, and only one QTL showed significant interactions with environments. Hence, a detailed presentation of results from QTL analyses for all traits is given based on means across environments. No QTL analyses were performed for GYR, because $\hat{\sigma}_{\mathrm{g}}^{2}$ was not significant for this trait.

\section{SCB Ratings}

In composite interval mapping for 1SCB ratings, we selected a total of 14 RFLP markers as cofactors (Table 3 , footnote). Ten putative QTL located on Chromosomes 1, 2 (two QTL), 5 (two QTL), 7, 8, 9 (two QTL), and 10 were found to significantly affect $1 \mathrm{SCB}$ ratings. LOD scores ranged from 2.5 on Chromosome 10 to 5.8 on Chromosome 1. The latter QTL explained $15.4 \%$ of $\hat{\sigma}_{\mathrm{p}}^{2}$, whereas the other QTL explained between 7.2 and

Table 2. Phenotypic $\left(r_{p}\right)$ and genotypic $\left(r_{\mathrm{g}}\right)$ (printed with underscore) correlation coefficients among 1SCB ratings, grain yield under protection (GYP), grain yield under infestation (GYI), grain yield reduction (GYR), and plant height (PHT) for the $215 \mathrm{~F}_{3}$ lines from cross CML $131 \times$ CML67, also $r_{p}$ between agronomic traits of $171 F_{3}$ lines and RFLP data of their parental $F_{2}$ plants. $\dagger$

\begin{tabular}{|c|c|c|c|c|c|c|c|}
\hline & \multicolumn{5}{|c|}{ Agronomic traits } & \multicolumn{2}{|c|}{ Genome composition } \\
\hline & 1SCB ratings & GYP & GYI & GYR & PHT & \%Heterozyg. $\ddagger$ & $\%$ CML1318 \\
\hline $\begin{array}{l}\text { 1SCB ratings } \\
\text { GYP }\end{array}$ & $-0.23^{+}$ & -0.11 & $\begin{array}{r}-0.16^{*} \\
0.62^{* *}\end{array}$ & $\begin{array}{l}-0.05 \\
-0.25^{* *}\end{array}$ & $\begin{array}{l}0.00 \\
0.29^{* *}\end{array}$ & $\begin{array}{l}0.00 \\
0.25^{* *}\end{array}$ & $\begin{array}{r}0.60^{* *} \\
-0.17^{*}\end{array}$ \\
\hline GYI & $=0.29++$ & $\underline{0.98}^{++}$ & & $0.45^{* *}$ & $0.33^{* *}$ & $0.29^{* *}$ & $-0.31^{* *}$ \\
\hline GYR & -1 & - & - & & 0.00 & $0.19^{*}$ & -0.15 \\
\hline $\begin{array}{l}\text { PHT } \\
\text { \%Heterozygosity }\end{array}$ & $\underline{0.15}^{+}$ & $\underline{0.27}^{+}$ & $\underline{0.55}^{+}$ & - & & $0.26^{* *}$ & $\begin{array}{l}0.23^{* *} \\
0.12\end{array}$ \\
\hline
\end{tabular}

*,** Phenotypic correlation was significant at the 0.05 and 0.01 probability level, respectively.

,+++ Genetic correlation exceeded one or two times its standard error, respectively.

+ 1SCB ratings, measured in three environments; GYP, GYI, GYR, and PHT, measured in two environments.

$\ddagger$ \% Heterozyg. = level of heterozygosity of parental $F_{2}$ individuals estimated from RFLP data.

$\$ \%$ CML131 = percentage of genome from the susceptible inbred CML131 estimated from RFLP data.

I Genotypic correlations were not estimated because $\sigma_{\mathrm{g}}^{2}$ for GYR was not significant $(P<0.01)$. 
$13.8 \%$ of $\hat{\sigma}_{\mathrm{p}}^{2}$. All alleles decreasing 1SCB ratings (i.e., increasing resistance to $1 \mathrm{SCB}$ feeding damage) were contributed by the resistant parent CML67. Seven QTL showed additive gene action, two partial dominance, and one displayed overdominance. A model fitting all ten putative QTL detected with composite interval mapping explained $65.0 \%$ of $\hat{\partial}_{\mathrm{p}}^{2}$ and $93.2 \%$ of $\hat{\sigma}_{\mathrm{g}}^{2}$. Although QTL analyses showed a considerable variation in the LOD plots for individual environments (Fig. 2), QTL $\times$ environment interactions were significant $(P<0.01)$ only for the estimated additive effect of the second QTL on Chromosome 9. Estimated additive effects at this QTL position varied between environments from 0.07 to -0.57 .

\section{Grain Yield under Protection}

Six markers, four of which were adjacent to subsequently detected QTL, were used as cofactors for composite interval mapping for GYP (Table 3, footnote). Six putative QTL affecting GYP were detected on Chromosomes 1, 2, 7, 8 (two QTL), and 9, explaining between 7.1 and $13.1 \%$ of $\hat{\sigma}_{\mathrm{p}}^{2}$ with LOD scores ranging from 2.6 to 5.1. A model fitting all six QTL explained $35.8 \%$ of $\hat{\sigma}_{\mathrm{p}}^{2}$ and 58.6 of $\hat{\sigma}_{\mathrm{g}}^{2}$. Both parents contributed alleles increasing GYP. Three QTL displayed overdominance.

\section{Grain Yield under Infestation}

Four markers were selected as cofactors for composite interval mapping of GYI (Table 3, footnote). Five putative QTL located on Chromosomes 2, 6, 8 (two QTL), and 10 were identified. These explained between 7.0 and $13.4 \%$ of $\hat{\sigma}_{\mathrm{p}}^{2}$ and had LOD scores ranging from 2.6 to 5.5. A model fitting all five putative QTL accounted for $35.4 \%$ of $\hat{\sigma}_{\mathrm{p}}^{2}$ and $48.5 \%$ of $\hat{\sigma}_{\mathrm{g}}^{2}$. All alleles increasing GYI were contributed by the resistant parent CML67, except for the second QTL on Chromosome 8. Two QTL showed partial dominance, one dominance, and two displayed overdominance. Only one QTL, located on Chromosome 8, was common to GYI and GYP.

\section{Plant Height}

For plant height, five markers were selected as cofactors for composite interval mapping (Table 3, footnote). Four putative QTL located on Chromosomes 2, 3, 4, and 5 were identified with LOD scores ranging from 2.8 to 9.2 . In a simultaneous fit, the four QTL explained $37.4 \%$ of $\hat{\sigma}_{\mathrm{p}}^{2}$ and $41.3 \%$ of $\hat{\sigma}_{\mathrm{g}}^{2}$. Plant height was increased by the CML131 allele at all QTL, except for the QTL detected on Chromosome 2. Two QTL showed additive gene action, one partial dominance, and one QTL displayed dominance.

\section{DISCUSSION \\ Genetic Foundation of 1SCB Resistance and Other Traits}

In our cross between a tropical and a subtropical inbred, we identified 10 QTL with significant effects on leaf feeding resistance against 1 SCB larvae. At all 10
QTL, the resistant allele was contributed by parental inbred line CML67, one of the most resistant lines out of CIMMYT's conventional stress breeding program. In developing this line, an attempt was made to combine all known sources of stem borer resistance. In contrast, parent CML131 is one of the most susceptible inbred lines developed by CIMMYT. It was chosen on the presumption that it does not contain alleles conferring resistance. Crosses among extreme genotypes increase the power of QTL detection (Lander and Botstein, 1989). Contrary to our findings, Schön et al. (1993) reported that in a population of $300 \mathrm{~F}_{3}$ lines derived from cross B73 $\times$ B52, two out of seven QTL affecting 2ECB resistance originated from the highly susceptible parent line B73.

By fitting all 10 QTL for 1SCB resistance in one model, $65.0 \%$ of $\hat{\sigma}_{\mathrm{p}}^{2}$ and $93.2 \%$ of $\hat{\sigma}_{\mathrm{g}}^{2}$ were detected. Estimates for the sum of additive genetic effects $(A=$ $\Sigma a_{\mathrm{i}}$, with summation over all QTL) and the sum of dominance effects $\left(D=\Sigma d_{\mathrm{i}}\right)$ amounted to $\hat{A}=-2.08$ and $\hat{D}=-0.50$ (Table 3 ). According to the results of a simulation study by Utz and Melchinger (1994), estimates of individual QTL effects as well as the variance explained by them can be inflated, particularly for smaller population sizes $(n \leq 300)$ and traits with moderate to low heritability $\left(h^{2}<0.4\right)$. In our experiment, an independent and unbiased estimate of $A$ can be obtained by comparison of generation means: $\tilde{A}=|\mathrm{P} 1-\mathrm{P} 2| / 2$ (Table 1). Estimates $\hat{A}$ and $\tilde{A}$ did not differ significantly, suggesting that the upward bias in estimating additive effects was negligible.

Hinderliter (1983) showed that in CIMMYT Population 27 the resistance against leaf feeding damage due to 1SCB larvae is a quantitative trait with primarily additive gene action. Thome et al. (1992) evaluated 10 maize inbred lines (five resistant and three susceptible CIMMYT lines, two public lines) in a diallel series of crosses for leaf feeding resistance to 1SCB, 1SWCB, and 1ECB. For all three insect species, general combining ability was highly significant for leaf damage ratings, whereas specific combining ability was only a minor source of variation. Schön et al. (1991, 1993) also identified QTL with mainly additive gene action for $1 E C B$ and 2ECB resistance in $F_{3}$ populations derived from two different crosses. These results indicate the predominance of additive gene action in the expression of resistance of maize against various insects species and are in harmony with our findings for $1 \mathrm{SCB}$.

Bergvinson et al. (1996) proposed that mechanisms of insect resistance in maize include protein, fibre, and cell wall phenolic acid contents as well as peroxidasemediated production of dehydrodiferulic acid. Four QTL for 1SCB resistance on Chromosomes 1, 2 (second QTL), 5 (first QTL), and 9 (second QTL), which together explained $57.0 \%$ of $\hat{\sigma}_{\mathrm{g}}^{2}$ for this trait, map to genomic regions that are known to carry genes involved in cell wall biochemistry. (i) Gene brittle stalk2 (bk2) on Chromosome 9 causes susceptibility to easy leaf breakage by effecting the stiffness and toughness of leaves. (ii) Genes bm 1 on Chromosome 5 and $b m 2$ on Chromosome 1 result in the brown midrib phenotype and lower content 

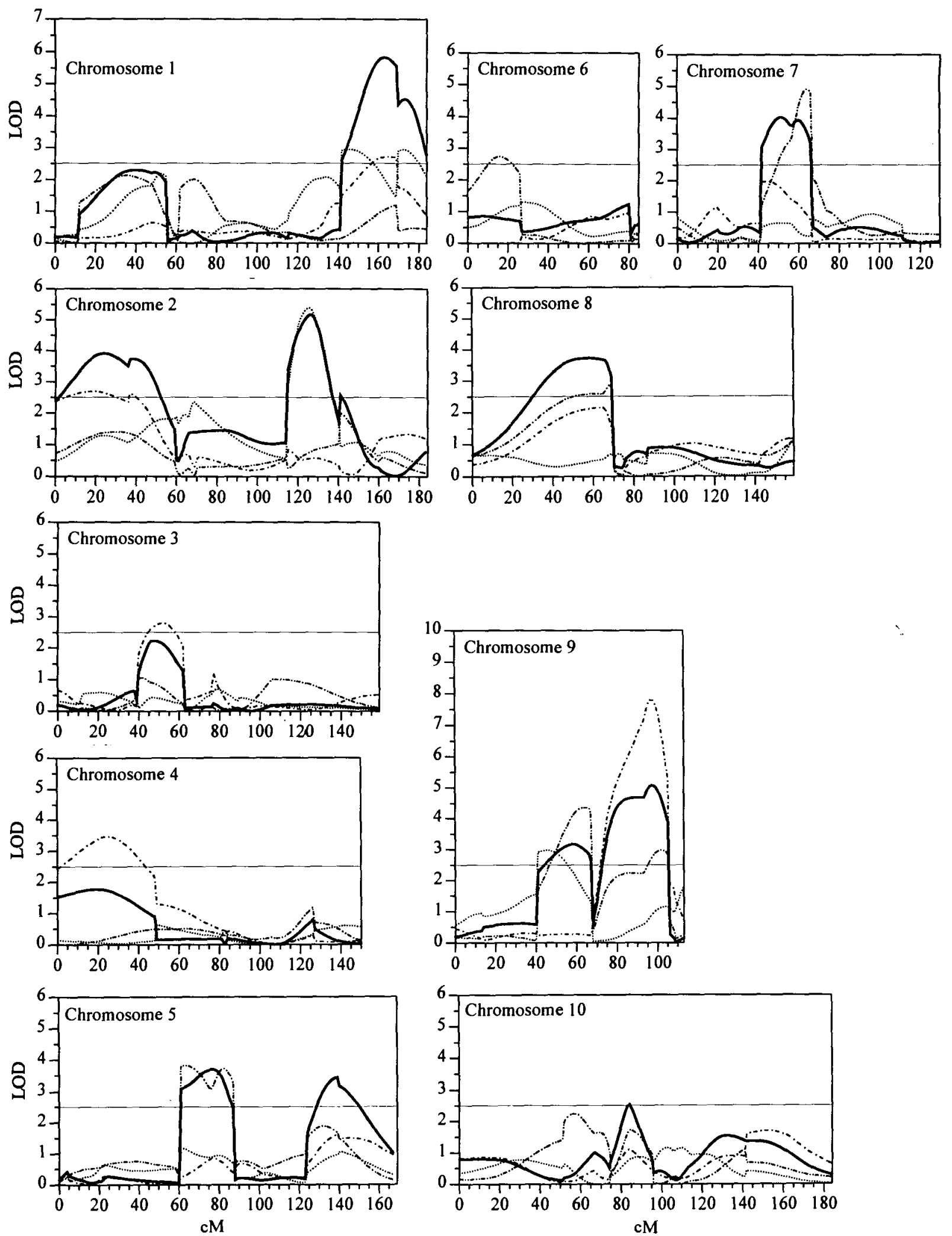

Fig. 2. QTL likelihood maps indicating LOD scores for 1 SCB ratings on Chromosomes 1 to 10 . A smooth curve was plotted through each LOD score, spaced every $1 \mathrm{cM}$. The horizontal line indicates the level of significance at LOD $=2.5$. Curves represent results from individual environments at Tlaltizapán $1992(-\cdots \cdots-)$, Tlaltizapán $1993----)$, Poza Rica $1993(-\cdots)$, and across environments (- - ). These results were obtained by applying composite interval mapping with PLABQTL.

of lignin, a major component in cell wall fortification. (iii) Gene peroxidasel ( $p x l)$ on Chromosome 2 may be involved in the production of dehydrodiferulic acid. According to the hypothesis proposed by Robertson
(1985), it may be speculated that the above-mentioned QTL simply represent different alleles at these loci with known major gene effects. In future research, a series of near-isogenic lines, which carry only specific single 
Table 3. Parameters associated with QTL significantly affecting 1SCB ratings, grain yield under protection, grain yield under infestation, and plant height. Biometrical parameters were estimated from phenotypic menas of $171 \mathrm{~F}_{3}$ lines from cross $\mathrm{CML131} \times \mathrm{CML67.} \dagger$

\begin{tabular}{|c|c|c|c|c|c|c|}
\hline \multirow[b]{2}{*}{ Chromosome } & \multirow[b]{2}{*}{ Position 8} & \multirow{2}{*}{$\begin{array}{l}\text { Max. } \\
\text { LOD }\end{array}$} & \multirow[b]{2}{*}{$R^{2} \mathbf{q}$} & \multicolumn{2}{|c|}{ Genetic effects $\ddagger$} & \multirow{2}{*}{$\begin{array}{l}\text { Gene } \\
\text { action\# }\end{array}$} \\
\hline & & & & Add. & Dom. & \\
\hline & & & $\%$ & 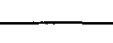 & - & \\
\hline \multicolumn{7}{|l|}{ 1SCB ratings $\dagger \dagger$} \\
\hline 1 & $152-\underline{-164}-170$ & 5.8 & 15.4 & -0.23 & 0.14 & PD \\
\hline 2 & $006-024-050$ & 3.9 & 11.2 & -0.20 & -0.18 & PD \\
\hline 2 & $116-126-134$ & 5.2 & 13.5 & -0.15 & -0.21 & OD \\
\hline 5 & $060-076-086$ & 3.7 & 10.1 & -0.26 & -0.01 & A \\
\hline 5 & $128-\underline{138}-152$ & 3.4 & 9.6 & -0.16 & -0.05 & A \\
\hline 7 & $040-052-068$ & 4.0 & 10.9 & -0.17 & -0.03 & A \\
\hline 8 & $032-\underline{056-070}$ & 3.7 & 10.4 & -0.24 & -0.11 & $\mathrm{PD}^{*}$ \\
\hline 9 & $040-058-068$ & 3.2 & 8.7 & -0.26 & 0.00 & A \\
\hline 9 & 079-098-106 & 5.1 & 13.8 & -0.25 & 0.02 & A \\
\hline 10 & 078-084-092 & 2.5 & 7.2 & -0.16 & -0.07 & $P^{*}$ \\
\hline \multirow[t]{2}{*}{ Total $\dagger \dagger$} & & 52.9 & 65.0 & -2.08 & -0.50 & \\
\hline & & & $\%$ & $\longrightarrow$ & - & \\
\hline \multicolumn{7}{|c|}{ Grain yield (protected) $\$ \S$} \\
\hline 1 & $130-\underline{140-156}$ & 3.4 & 9.1 & 6.77 & 0.03 & $\mathbf{A}$ \\
\hline 2 & $000-000-018$ & 2.7 & 7.6 & -3.34 & 8.91 & OD \\
\hline 7 & $116-126-130$ & 4.9 & 12.8 & -7.53 & 3.99 & PD* $^{*}$ \\
\hline 8 & 030-064-070 & 2.6 & 7.1 & 5.48 & -3.28 & PD* $^{*}$ \\
\hline 8 & 089-104-116 & 5.1 & 13.1 & -1.86 & 21.85 & OD \\
\hline 9 & $046-058-068$ & 2.9 & 7.7 & 0.15 & 6.74 & OD \\
\hline \multirow[t]{2}{*}{ Total } & & 16.4 & 35.8 & -0.33 & 38.24 & \\
\hline & & & $\%$ & $\longrightarrow$ & - & \\
\hline \multicolumn{7}{|c|}{ Grain yield (SCB infested) 19} \\
\hline 2 & $058-\underline{064-068}$ & 4.1 & 10.4 & 5.51 & 2.65 & PD \\
\hline 6 & $080-082-084$ & 5.5 & 13.4 & 7.69 & 6.09 & PD \\
\hline 8 & $074-\underline{076}-084$ & 2.6 & 7.0 & 7.87 & -7.01 & D \\
\hline 8 & 086-104-120 & 2.9 & 7.9 & -2.35 & 23.94 & OD \\
\hline 10 & 086-012-110 & 3.1 & 8.3 & 2.58 & 5.19 & OD \\
\hline \multirow[t]{2}{*}{ Total } & & 18.1 & 35.4 & 21.30 & 30.86 & \\
\hline & & & $\%$ & $\ldots$ & 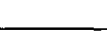 & \\
\hline \multicolumn{7}{|l|}{ Plant height\#\# } \\
\hline 2 & 058-062-066 & 4.6 & 12.0 & 3.56 & -0.13 & $\mathbf{A}$ \\
\hline 3 & $026-038-040$ & 3.5 & 9.2 & -5.20 & 0.41 & $\mathbf{A}$ \\
\hline 4 & $086-\underline{-094-102}$ & 9.2 & 21.4 & -6.23 & 4.30 & PD \\
\hline 5 & 000-002-006 & 2.8 & 7.9 & -2.88 & -2.23 & $\mathrm{PD}^{*}$ \\
\hline Total & & 19.9 & 37.4 & -10.8 & 2.35 & \\
\hline
\end{tabular}

† 1SCB ratings, measured in three environments; all other traits, measured in two environments. Analyses was performed with software package PLABQTL.

‡ Estimates were obtained from a simultaneous fit of all putative QTL.

\$ Positions of likelihood peak (maximum LOD) with underscored letters plus support interval in centimorgans relative to the first RFLP marker on chromosome (Fig. 1).

I $R^{2}=$ square of partial correlation coefficient in \%.

\# $\mathrm{A}=$ additive gene action $\left(\left|\mathrm{d}_{i}\right| /\left|\mathrm{a}_{i}\right|<0.2\right), \mathrm{PD}=$ partial dominance $\left(0.2<\left|\mathrm{d}_{i}\right| /\left|\mathrm{a}_{i}\right|<0.8\right), \mathrm{D}=$ dominance $\left(0.8<\left|\mathrm{d}_{i}\right| /\left|\mathrm{a}_{i}\right|<1.2\right)$, OD $=$ overdominance $\left(\left|\mathrm{d}_{i}\right| /\right.$ $\left.\left|\mathrm{a}_{l}\right|>1.2\right), \mathrm{PD}^{*}=$ dominance effect of $\mathrm{QTL}$ was not significantly different from zero to probability level $P<0.1$.

$\dagger+$ Marker cofactors in the order of selection: csu59, bnl5.71, csu37, bnl7.49b, umc12, bnl6.06, umc6, bnl8.29, umc127, umc167, csu30, umc123, umc153, csu70.

持 Estimates of total LOD score and total $R^{2}$ were obtained from a simultaneous fit of all putative OTL affecting the respective trait.

$\$ 8$ Marker cofactors in the order of selection: csu133, bnl5.47, umc47, umc150a, csu48, umc123.

If Marker cofactors in the order of selection: csu133, bnl5.47, umc47, umc150a.

\# Marker cofactors in the order of selection: umc35, umc106, bnl14.28, umc12, csu70.

QTL for 1SCB resistance, may be used for fine mapping of each QTL region according to the approach described by Paterson et al. (1991) and for verification of their allelism with known major genes.

In total, we detected four QTL significantly affecting PHT. One of the QTL regions on Chromosome 3 was also reported by Schön et al. (1993). Only for one of the six QTL for GYP and five for GYI, QTL support intervals overlapped, even though the genotypic correlation was very high for both traits. Two reasons may account for the discrepancy between the magnitude of the $r_{\mathrm{g}}$ and the number of QTL in common: (i) all QTL identified for GYP and GYI explained only about half of $\hat{\sigma}_{g}^{2}$, respectively, indicating that several major and minor QTL remained undetected; (ii) the genotypic correlation between the two traits was overestimated. 


\section{QTL $\times$ Environment Interactions}

For all traits under consideration, variance component $\hat{\sigma}_{\mathrm{ge}}^{2}$ was highly significant, yet $\hat{\sigma}_{\mathrm{qe}}^{2}$ was significant only for 1 SCB resistance. The fact that we were able to demonstrate significant QTL $\times$ environment interaction for only one QTL reflects the low power of the statistical test due to the small number of environments in our study. A thorough analysis of QTL $\times$ environment interactions would require increasing the number of test environments. Differences in the peaks of LOD graphs as observed in Fig. 2 provide a weak indication for the presence of QTL $\times$ environment interaction, because this interaction is not part of the genetic model fitted (Jansen et al., 1995). As stated by these authors, even in the absence of true QTL $\times$ environment interactions, the chance of simultaneous detection of a QTL in several environments is small.

\section{Relationship between Heterozygosity and Performance of $F_{3}$ lines}

Our RFLP data of the parental $F_{2}$ plants revealed a great variation in their degree of heterozygosity as predicted by theory (Franklin, 1977). Numerous studies, especially generation mean analyses, in maize and other allogamous crops have demonstrated a close association between the degree of heterozygosity of plants and their performance level for heterotic traits such as plant vigor and yield. For backcross progenies of the elite cross B73 $\times$ Mo17, Stuber et al. (1992) reported tighter correlations of heterozygosity, determined with RFLPs, with grain yield $\left(r_{\mathrm{p}}=0.68\right)$ and PHT $\left(r_{\mathrm{p}}=0.50\right)$ compared with our findings (Table 2). Possible reasons to explain these discrepancies include (i) a lower heterosis for GYP in cross CML131 $\times$ CML67; (ii) use of $F_{3}$ lines instead of backcross progenies, which are expected to display twice the amount of heterosis; and (iii) a lower accuracy of our GYP measurements due to a smaller number of test environments.

\section{Conclusions for Conventional and MAS Breeding Programs}

Efficiency of indirect selection depends on (i) the genetic correlation between the selected trait and the target trait, and (ii) a high heritability of the selected trait (Falconer, 1989). While Thome et al. (1994) found a significant phenotypic correlation $\left(r_{\mathrm{p}}=0.63\right)$ between ISWCB ratings and GYR, no significant correlation between 1SCB ratings and GYR were observed in the present study. This result is probably attributable to the low precision of our GYR measurements determined from adjacent trials, as indicated by the low $h^{2}$ estimate and the large standard error associated with $\hat{\sigma}_{\mathrm{g}}^{2}$. Another explanation for this result is that by assessing the leaf damage caused by SCB larval feeding, we addressed only the antibiosis component of resistance, which by definition refers to a stunting in the development of insects feeding on resistant plants. Tolerance, the second component of resistance, defined as the ability of a genotype to outgrow leaf damage, was not taken into account.
Because tolerance strongly depends on plant vigor, it may vary considerably among $\mathrm{F}_{3}$ lines, as suggested by the significant correlation between heterozygosity with GYR and GYI (Table 2). Hence, a tight correlation between GYR and 1SCB ratings cannot be expected in the presence of variation for tolerance. Thome et al. (1994) eliminated the masking effect of tolerance by using hybrids out of a series of diallel crosses between resistant and susceptible inbreds. The significant correlation between 1 SWCB ratings and GYR reported by these authors clearly demonstrates the importance of antibiosis on stabilizing grain yield under larval attack. Further research is warranted to investigate both components of insect resistance in future QTL mapping studies.

Quantitative traits are conventionally improved by applying recurrent selection procedures. The relatively small number of genes involved in leaf feeding resistance to 1SCB as well as the additive type of gene action found in our study suggests that all methods of recurrent selection should be highly effective for improving the antibiosis type of resistance. Full-sib selection is one attractive option, because the trait can be measured before flowering and, hence, two selection cycles can be completed in one year. Alternatively, S1 line selection should result in a $30 \%$ higher selection gain per cycle for traits with pure additive gene action, but only one cycle can be completed per year. Thus, if the breeder wants to improve only antibiosis, our results from QTL mapping would suggest a superiority of full-sib selection with two cycles per year over S1 line selection with one cycle per year.

We have studied 1SCB resistance for line per se performance. With regard to applications in hybrid breeding, 1SCB resistance of hybrid combinations is a major objective. Due to the preponderance of additive gene action found for 1SCB resistance, a high correlation between line per se and testcross performance can be expected for this trait but we have found no published reports on this issue. A breeding procedure based on line per se performance is attractive, because at least twice the genotypic variance can be exploited for selection compared to testcrosses. However, for obtaining a high level of resistance in a hybrid, both parental inbred lines need to be resistant. Generally, it will not be sufficient to cross a highly resistant line with a susceptible line to obtain a resistant hybrid. Other experiments at CIMMYT showed that in specific hybrid combinations between resistant and susceptible tropical inbred lines, some negative heterosis for 1SCB ratings can occasionally be observed (D.C. Jewell, 1995, personal communication).

The knowledge gained in this study can be used directly in setting up a MAS program. The QTL on Chromosomes $1,2,5$, and 9 are candidates for incorporating leaf feeding resistance against $1 \mathrm{SCB}$ into lines with good general combining ability for yield but poor insect resistance. Rapid transfer of these QTL alleles into susceptible inbreds can be accomplished by marker-assisted backcrossing. Marker information can be employed in selecting for the desired genomic regions as well as against remainder genome of donor line CML67. It remains to be established whether the putative QTL regions on 
Chromosomes 1, 2, 5, and 9 have negative effects on other important traits such as digestibility of stover or lodging resistance, which were not evaluated in this study. We are presently conducting further experiments with recombinant inbred lines to confirm the results from this study and to narrow down the genomic regions conferring resistance to $1 \mathrm{SCB}$.

\section{ACKNOWLEDGMENTS}

The present study is part of EUREKA project 290, which is a collaboration network on Application of RFLPs in Corn Breeding between the Institute of Cereal Research at Bergamo, Italy, Groupe Limagrain, Chappes, France, KWS Kleinwanzlebener Saatzucht AG, Einbeck, Germany, Orsan, Inc., Paris, D.J. van der Have, Kappelle, the Netherlands, and CIMMYT, Mexico. This research was supported by grants from the Vater und Sohn Eiselen-Stiftung, Ulm, Germany. We thank Drs. D. Beck, C. Jiang, and M. Ribaut for reviewing the manuscript. The skilled technical assistance of F. Acevedo is gratefully acknowledged.

\section{REFERENCES}

Beavis, W.D., O.S. Smith, D. Grant, and R. Fincher. 1994. Identification of quantitative trait loci using a small sample of topcrossed and $F_{4}$ progeny from maize. Crop Sci. 34:882-896.

Bergvinson, D., J.T. Arnason, J.A. Mihm, and D.C. Jewell. 1996. Phytochemical basis for multiple borer resistance in maize. CIMMYT. Insect Resistant Maize: Recent Advances and Utilization Proceedings of the international symposium, Mexico City (in press).

Bliss, C.I. 1967. Statistics in biology. Vol. I. McGraw-Hill Book Company, London.

Burr, B., F.A. Burr, K.H. Thompson, M.C. Albertson, and C.W. Stuber. 1988. Gene mapping with recombinant inbreds in maize. Genetics 118:519-526.

CIMMYT Maize program. 1991. Announcement of CIMMYT inbred lines CML1 to CML139. Mexico City.

Elias, L.A. 1970. Maize resistance to stalk borers in Zeadiatraea Box and Diatraea Guilding (Lepidoptera: Pyralidae) at five locations in Mexico. Ph.D. thesis, Kansas State University, Manhattan, KS.

Falconer, D.S. 1989. Introduction to quantitative genetics. 3nd ed. Longman, London.

Franklin, I.R. 1977. The distribution of the proportion of the genome which is homozygous by descent in inbred individuals. Theor. Pop. Biol. 11:60-80.

Gardiner, J.M., E.H. Coe, S. Melia-Hancock, D.A. Hoisington, and S. Chao. 1993. Development of a core RFLP map in maize using an immortalized $F_{2}$-population. Genetics 134:917-930.

Haldane, J.B.S. 1919. The combination of linkage values, and the calculation of distance between the loci of linked factors. J. Genet. 8:299-309.

Haley, C.S., and S.A. Knott. 1992. A simple regression method for mapping quantitative trait loci in line crosses using flanking markers. Heredity 69:315-324.

Hinderliter, D.G. 1983. Host plant resistance in two tropical maize, Zea mays L., populations to southwestern corn borer, Diatraea grandiosella Dyar, and the sugarcane borer, D. saccharalis $\mathrm{F}$. Ph.D thesis, University of Wisconsin, Madison (DA8325519).

Hoisington, D.A., M. Khairallah, and D. González-de-León. 1994. Laboratory protocols: CIMMYT Applied molecular genetics laboratory. 2nd ed. Mexico City.

Holm, S. 1979. A simple sequentially rejective multiple test procedure Scand. J. Statist. 6:65-70.

Jansen, R.C. 1994. Controlling the Type I and Type II errors in mapping quantitative trait loci. Genetics 138:871-881.

Jansen, R.C. 1993. Interval mapping of multiple quantitative trait loci. Genetics 135:205-211.

Jansen, R.C., and P. Stam. 1994. High resolution of quantitative traits into multiple loci via interval mapping. Genetics 136:14471455.

Jansen, R.C., J.W. Van Ooijen, P. Stam, C. Lister, and C. Dean.
1995. Genotype-by-environment interaction in genetic mapping of multiple quantitative trait loci. Theor. Appl. Genet. 91:33-37.

Knapp, S.J. 1994. Mapping quantitative trait loci. p. 58-96, In R.I. Phillips and I.K. Vasil (ed.) DNA-based markers in plants. Kluwer Academic Publishers, Dordrecht, the Netherlands.

Lander, E.S., and D. Botstein. 1989. Mapping Mendelian factors underlying quantitative traits using RFLP linkage maps. Genetics 121:185-199.

Lander, E.S., P. Green, J. Abrahamson, A. Barlow, M.J. Daly, S.E. Lincoln, and L. Newburg. 1987. MAPMAKER: an interactive computer package for constructing primary genetic linkage maps of experimental and natural populations. Genomics 1:174-181.

Lee, M. 1995. DNA markers and plant breeding programs. Adv. Agron. 55:265-344.

Mihm, J.A., D.C. Jewell, and J.A. Deutsch. 1991. Annu. Plant Resistance to Insects Newsl. 17:69-71.

Mihm, J.A. 1985. Breeding for host plant resistance to maize stem borers. Insect Sci. Appl. 6:369-377.

Mihm, J.A. 1983. Efficient mass rearing and infestation techniques to screen for host plant resistance to maize stem borers, Diatraea spp. CIMMYT. El Batan, Mexico.

Mode, C.J., and H.F. Robinson. 1959. Pleiotropism and the genetic variance and covariance. Biometrics 15:518-537.

Paterson, A.H., S. Damon, J.D. Hewitt, D. Zamir, H.D. Rabinowitch, S.E. Lincoln, E.S. Lander, and S.D. Tanksley. 1991. Mendelian factors underlying quantitative traits in tomato: Comparison across species, generations, and environments. Genetics 127:181197.

Paterson, A.H., E.S. Lander, J.D. Hewitt, S. Peterson, S.E. Lincoln, and S.D. Tanksley. 1988. Resolution of quantitative traits into Mendelian factors by using a complete linkage map of restriction fragment length polymorphisms. Nature 335:721-726.

Robertson, D.S. 1985. A possible technique for isolating genic DNA for quantitative traits in plants. J. Theor. Biol. 117:1-10.

Schön, C.C., M. Lee, A.E. Melchinger, W.D. Guthrie, and W.D. Woodman. 1993. Mapping and characterization of quantitative trait loci affecting resistance against second-generation European corn borer in maize with the aid of RFLPs. Heredity 70:648-659.

Schön, C.C., A.E. Melchinger, M. Lee, W.L. Woodman, and W.D. Guthrie. 1991. RFLP mapping of QTLs for resistance to European corn borer in maize. IV.P20. In Eucarpia Symposium on Genetic Manipulation in Plant Breeding. Reus/Salou (Tarragona), Spain. 26-30 May 1991. IRTA, Reus/Salou (Tarragona), Spain.

Scott, G.E., and F.M. Davis. 1974. Effect of southwestern corn borer feeding on maize.Agron. J. 66:773-774.

Searle, S.R. 1971. Linear models. John Wiley \& Sons, New York.

Smith, M.E., J.A. Mihm, and D.C. Jewell. 1989. Breeding for multiple resistance to temperate, subtropical, and tropical maize insect pests at CIMMYT. p. 222-234. In Toward insect resistant maize for the third world. Proc. Int. Symp. Methodologies for Developing Host Plant Resistant to Maize Insects, El Batan, Mexico. 9-14 March 1987. CIMMYT, El Batan, Mexico.

Stuber, C.W., S.E. Lincoln, D.W. Wolff, T. Helentjaris, and E.S Lander. 1992. Identification of genetic factors contributing to heterosis in a hybrid from two elite maize inbred lines using molecular markers. Genetics 132:823-839.

Stuber, C.W., M.D. Edwards, and J.F. Wendel. 1987. Molecular marker-facilitated investigations of quantitative trait loci in maize. II. Factors influencing yield and its component traits. Crop Sci. 27:639-648

Thome, C.R., M.E. Smith, and J. Mihm. 1994. Yield reduction in an maize diallel under infestation with southwestern corn borer. Crop Sci. 34:1431-1435.

Thome, C.R., M.E. Smith, and J. Mihm. 1992. Leaf feeding resistance to multiple insect species in a maize diallel. Crop Sci. 32:14601463.

Utz, H.F., and A.E. Melchinger. 1994. Comparison of different approaches to interval mapping of quantitative trait loci. p. 195204. In J.W. van Ooijen, and J. Jansen (ed.) Proceedings of the Ninth Meeting of the EUCARPIA Section Biometrics in Plant Breeding, Wageningen, the Netherlands.

Utz, H.F., and A.E. Melchinger. 1995. PLABQTL. A Computer Program to Map QTL. Institute of Plant Breeding, Seed Science, and Population Genetics. Univ. of Hohenheim, Stuttgart, Germany.

Zeng, Z.B. 1994. Precision mapping of quantitative trait loci. Genetics 136:1457-1468. 